\title{
Preparing students for physics-intensive careers in optics and photonics
}

\author{
Benjamin M. Zwickl and Javier Olivera \\ School of Physics and Astronomy, Rochester Institute of Technology, Rochester, NY 14623 \\ Kelly Norris Martin and Kirk M. Winans \\ School of Communication, Rochester Institute of Technology, Rochester, NY 14623
}

\begin{abstract}
Preliminary results are presented from an ongoing study that is investigating both academic and industrial career paths in optics and photonics. By grounding the discussion of workforce development in education research, it will be possible to have more productive discussions and a more accurate understanding of contentious topics such as skills gaps, shortages of skilled STEM workers, and similarities and differences between academic and industrial careers. The study is clarifying how specific math, physics, and communication skills are utilized in academic and industrial labs. Initial results indicate significant use of computational mathematics in the workplace and communication modes that extend beyond technical writing, including group work, critiquing, one-on-one training, documenting, and more. Physics departments trying to link their curriculum with students' future careers will likely benefit from these findings, which also serve as a case study for directly linking physics education research with national priorities in workforce development.
\end{abstract}

PACS numbers: 01.40.Fk,01.40.gb,01.50.Pa,01.50.Qb

\section{INTRODUCTION}

There are several frequently cited motives for improving STEM education, including improving the scien-tific literacy of the general population and increasing the diversity of STEM professionals. However, the mo-tive that seems to build consensus across political aisles and throughout geographic regions is the link between STEM education and the economic prosperity of indi-viduals and communities. The Mission Statement of the National Science Foundation, a primary funder of STEM education and Discipline-Based Education Re-search, says that "In order to unleash the Nation's inno-vation potential, a well-prepared knowledge workforce...is essential [1]." The National Academies have emphasized the link between STEM education and economic well-being [2]. The American Institute of Physics tracks statis-tical trends in physics jobs [3], and the American Physi-cal Society is renewing efforts to inform students about a broad range of careers through the APS Careers in Physics project. Most recently, the ongoing APS/AAPT Joint Task Force on Undergraduate Physics Programs (J-TUPP) is charged with answering "What skills and knowledge should the next generation of undergraduate physics degree holders possess to be well prepared for a diverse set of careers [4] ?"

Given that there is broad recognition of the link between STEM education and jobs, there is surprisingly little research directly studying how students' learning transfers into the workplace. Instead, most PER has focused on improving learning within the undergraduate curriculum. The 2012 NRC summary report on Discipline-Based Education Research, while acknowledging workforce development as a key motive for DBER, only mentions the term "workforce" in introductory remarks and not in the extensive literature review of prior DBER [5]. In addition to the lack of research, there is sion between higher education and industry. There are frequent claims of skills gaps and shortages from employers, and claims that college graduates are not job-ready even at the $\mathrm{PhD}$ level [6]. Yet personal conversations with faculty reveal a concern about catering to the needs of industry, which may elevate niche skills above broader critical thinking and diminish the value of the individual as merely a member of a corporate workforce. Furthermore, industry surveys often utilize private research firms which are disconnected from the rest of the DBER community, and the reports generated by those firms do not have consistent standards for reporting of methodology as would be expected in peer-reviewed DBER literature. In summary, there is a lack of prior research in PER, shortcomings in prior research supported by industry, and a strong consensus that education impacts jobs and economic well-being. There is a need to bridge the gap between PER and workforce preparation.

\section{STUDY DESIGN}

Three broad research questions have guided the design and direction of the study: (1) What is the evidence for a skills gap between school and work for recent hires into photonics careers? (2) How do different groups (employers, employees, graduate research advisors, graduate research assistants) perceive the key aspects of career readiness? (3) How are math, physics, and communication skills being utilized in the workplace?

Because the prior research on these topics is scant and popular press often reports conflicting views of a skills gap (i.e., disagreement about whether the gap is largest in technical skills or soft skills), we are employing grounded theory methodology to build our case from the data. The primary data sources are semi-structured individual interviews with a wide range of people involved ten- 
TABLE I. Current and projected study population.

\begin{tabular}{l|c|c}
\hline \hline & Current $(N=10)$ & Est. $2017(N=110)$ \\
\hline Industry Managers & 3 & 30 \\
Recent Hires & 2 & 30 \\
PhD Advisors & 2 & 20 \\
PhD Students & 3 & 30 \\
\hline \hline
\end{tabular}

in photonics engineering, research, and manufacturing in the Rochester, NY region. The focus on photonics is locally relevant, because Rochester is home to over 60 small, medium and large companies dealing with optical components, optical systems, lasers, and imaging, along with two universities and one community college with strong emphases in optics. Photonics is also relevant because it is a field closely linked to physics and heavily utilizes ideas from electricity and magnetism, optics, and quantum mechanics, which are core undergraduate courses. In addition, there is a national effort to promote photonics as a cohesive STEM discipline [7].

Because much previous research on skills gaps has limited its focus to the needs and wants of employers and largely neglected the voice of entry-level employees, we are sampling both supervisors and entry-level employees. Because photonics is well-represented in academic research and industry, we have included graduate research assistants (as entry-level academics) and their PhD advisors (as supervisors) in the study population. Within industry, we are interviewing employees during their first two years of employment, while in graduate school we are interviewing graduate research assistants at any stage in their research. Table I summarizes the current and projected participation numbers. Of the 10 participants described in this study, seven are involved in research or engineering as an entry-level worker or supervisor. The other three include a technician (with some community college experience), a supervisor of technicians, and a human resources manager.

The interview protocol is semi-structured. The protocol begins by learning about the person's role and experience in the company or university research lab. The conversation about skills is initiated by asking "What skills do you think are most important for success in your company/research group?" For entry-level employees and grad students, we ask follow-up questions to learn how proficient he/she felt upon starting their job, how they developed their skills, and if there are areas they are trying to improve. This initial phase of the interview makes no effort to constrain the meaning of skills and gives us the broadest look at a skills gap. The more content-specific portions of the interview come later. For instance, we ask "What kinds of math do you use on the job? For what purposes or goals? What tools are used?" Similar questions are asked regarding communication, physics, and optics. Because we are trying to understand how skills are used in the workplace, we en- courage interviewees to clarify the context. Rather than collecting generic statements about the importance of calculus, we want to understand the real-world situations where calculus is being applied, how frequently, and with what tools (e.g., pencil and paper, MATLAB, etc.). Each interview lasts 45-60 minutes, and consists of about 50006000 words. Interviews are transcribed using a transcription service.

The interviews were iteratively coded. During the first iteration, 3 or 4 of the authors individually conducted an open/initial coding process in order to identify all statements that were aligned with our broad research questions. The codes were either short fragments of quoted text, or a short phrase to summarize the idea. In a second phase, all four authors came together to share their coded segments and broadly categorize them. The second phase ensured that all statements of interest were identified, and the group categorization allowed the authors to codevelop the broad coding definitions. After coded statements from 7 interviews were aggregated, we developed a preliminary coding dictionary. Disagreements between coders were resolved by restructuring the codes and/or clarifying definitions. The coding dictionary serves as a summary of the breadth of our emergent themes, and as an analysis tool for efficient coding of future interviews as the study population is enlarged. Our current set of nine high-level emergent codes includes: Where Learning Happens, Communication, Math, Physics, Technical Skills, Fit/Personality, Intangibles, Organizational Culture, and Structural Ties (between higher education and industry). Each high-level code has one or two additional levels of sub-codes, similar to Table II. In addition, the full coding dictionary provides definitions and typical examples. For example, the Communication sub-code Public Speaking has several sub-sub-codes (e.g., Opportunities for Public Speaking) with definitions (e.g., observations about a presentation that required preparation and typically has higher stakes), and typical examples (e.g., "...persuasive presentations to funding agencies, such as SBIR grants.") In this way, the coding dictionary is both an analytical tool and a rich synthesis of emergent results.

\section{RESULTS}

We discuss three preliminary results through the use of the emergent coding frameworks, the frequency of particular codes, and quotes from interviewees.

\section{A. Where skill development happens}

Our first broad research question is about the evidence for a skills gap in the Rochester photonics industry. Much of the national discussion around skills gaps is framed as a deficiency in job applicants' skills, typically as a result of the insufficient quantity or quality of prior education. However, this framing potentially oversimplifies 
workforce development and ignores the possibility that employers may play a significant role in developing skills in their employees and that the workplace becomes an environment for learning.

The emergent high-level code Where Learning Happens divides experiences into three categories: education prior to employment, education during employment, and beneficial life experiences. Prior to employment, both academic coursework and outside-the-classroom experiences (e.g., internships and research experiences) were identified as important places where skills were developed. All supervisors said internships or undergraduate research were sought after experiences in new employees. Also, entry-level engineers and PhD students acknowledged their own growth as a result of undergrad research and co-ops. The internship and research experiences provide exposure to a professional work environment and the opportunity to work on complex, real-world engineering and scientific projects.

Within the workplace, an even larger number of training options were cited, including apprenticeships, rotation programs, formal on-the-job training (both internally and externally developed), and employer-supported continuing education through local community colleges and universities. Although these employers would appreciate a higher level of prior training, they are proactively investing resources in their employees and seeking support from regional, state, and federal workforce development grants. Finally, employees' prior life experiences provided skill development opportunities. For example, hobbies were cited as common ways to develop hands-on skills with tools and machines and to develop computer programming skills.

One implication is that career development is a complex process that involves more than just alignment between higher education and industry. There needs to be a holistic view of learning STEM skills that includes the education system, employers, and other life experiences.

\section{B. Computational and analytic math use}

Our third major research question focuses on the use of math, physics, and communication in the workplace. This question is significant because it connects workplace skills to issues integral to physics education and PER. One aspect of math use that we are studying is the use of mathematical tools on the job. By tools we mean pencil and paper, analytic/symbolic math, calculators, Excel, MATLAB (and similar programs), and more. All seven engineers and researchers said computational mathematical methods are essential for a range of common workplace tasks, including simulation, device design, and data analysis. Six out of those seven frequently used MATLAB. Beyond general purpose computational math environments, commercial finite element analysis software (e.g., COMSOL Multiphysics) was used for modeling the behavior of more complex and realistic systems. Appli- cations of finite element analysis included wave propagation, EM fields, and mechanical deformation under stress and thermal changes. While the use of finite element analysis is not as pervasive as MATLAB, it was expected for some engineers and $\mathrm{PhD}$ students.

Although computational math is heavily used on a day-to-day basis in both academia and industry, symbolic/analytic math appears to have a more specific and specialized use. A supervisor of engineers said, "[Symbolic math] is not used because we have so many technicians here...It's one of those things where I expect anyone with their Masters or PhD to be able to read it and understand it. But in communicating, it's because there are so many people here who cannot speak math,...we just get out of the habit of using it." A PhD advisor admitted that, "There's not a lot of need to solve an integral or something like that. It hasn't come up very often in the last many years." Both of these supervisors said computational skills were essential for the job. However, a grad student did provide some insight into the utility of symbolic math. "For me, the pencil and paper math is really good when...I'm just starting to play with a new idea for something. For that it's easier for me to sit down with pencil and paper and sort of write things out."

In these interviews, the primary utility of analytic math is expressing the new ideas necessary for conducting research. Journal articles and textbooks almost always utilize symbolic and analytic math for communicating ideas and relationships, while computational math is generally utilized for its speed and ability to handle more realistic and complex problems.

Faculty thought students should have programming skills, yet admit providing little formal training in their curriculum. Given the prevalence of computational methods and several graduate students who admitted to having little prior preparation, the data supports physics education efforts to incorporate computation more systematically into the undergraduate curriculum.

\section{Workplace communication modes}

Within the undergraduate physics curriculum, the most common graded communication activity is the formal lab report, which is a form of technical writing. However, the workplace communication activities documented in our interviews are much more diverse, as Table II shows. Within written communication, there has been a strong emphasis on documentation. When asked about areas where entry-level engineers could improve, one supervisor of engineers said, "Documentation...and not only with formal documentation but even in any type of written communication keeping people apprised of what they're doing. They don't share information." Similarly, a graduate student had this reflection on documentation, "Oh my gosh...the number of times I've had to be like 'Oh, I can't remember, have I done this before? Have I checked this thing out before?' [It is] so impor- 
TABLE II. Abbreviated emergent codebook for communication-related sub-codes, which highlights a broad range of communication practices used in the workplace.

\begin{tabular}{|c|c|c|}
\hline Sub-code & $\begin{array}{l}\text { Sub-sub- } \\
\text { code }\end{array}$ & Definition \\
\hline \multirow[t]{2}{*}{$\begin{array}{l}\text { Collaboration } \\
\text { and group } \\
\text { work }\end{array}$} & Mentoring & $\begin{array}{l}\text { Supervisor to supervisee men- } \\
\text { toring or providing instruc- } \\
\text { tion. }\end{array}$ \\
\hline & Teamwork & $\begin{array}{l}\text { Working as a team or a group } \\
\text { to offer support (knowledge, } \\
\text { equipment, social) or solve a } \\
\text { problem. }\end{array}$ \\
\hline \multirow[t]{4}{*}{ Written } & $\begin{array}{l}\text { Documenta- } \\
\text { tion }\end{array}$ & $\begin{array}{l}\text { Any kind of reporting on sta- } \\
\text { tus/progress or log. }\end{array}$ \\
\hline & $\begin{array}{l}\text { Reading and } \\
\text { Interpreting }\end{array}$ & $\begin{array}{l}\text { Reading, interpreting, and fol- } \\
\text { lowing written instructions. }\end{array}$ \\
\hline & $\begin{array}{l}\text { Technical } \\
\text { writing }\end{array}$ & $\begin{array}{l}\text { Communicating findings and } \\
\text { background research as in a } \\
\text { journal article. }\end{array}$ \\
\hline & Email & $\begin{array}{l}\text { How students/employees com- } \\
\text { municate through email. }\end{array}$ \\
\hline \multirow[t]{3}{*}{ Visual } & Reports & $\begin{array}{l}\text { Written reports where layout } \\
\text { and visual communication is } \\
\text { important. }\end{array}$ \\
\hline & Slides & $\begin{array}{l}\text { Slides used for oral presenta- } \\
\text { tions (for group or one-on-one) }\end{array}$ \\
\hline & $\begin{array}{l}\text { Body Lan- } \\
\text { guage }\end{array}$ & $\begin{array}{l}\text { Discussion of how people look, } \\
\text { act, or move, including "body } \\
\text { language." }\end{array}$ \\
\hline $\begin{array}{l}\text { Interpersonal } \\
\text { Communica- } \\
\text { tion }\end{array}$ & & $\begin{array}{l}\text { Communicating one-to-one, } \\
\text { between individuals. }\end{array}$ \\
\hline $\begin{array}{l}\text { Public } \\
\text { Speaking }\end{array}$ & & $\begin{array}{l}\text { Formal presentations to a } \\
\text { group of two or more. }\end{array}$ \\
\hline
\end{tabular}

tant to keep a good written lab notebook or electronic lab notebook." Despite some fairly definitive statements about the value, we did not find a common set of best practices for documentation. One academic group only saved data with minimal additional notes, but was experimenting with electronic lab notebooks, while a second academic group used PowerPoint slides, and a company used formal progress reports.

A general theme is that supervisors in academia and industry say communication skills are a significant weakness among incoming employees and graduate research assistants. Among supervisors, there was a general satisfaction with technical ability and an expectation that the technical tasks could get done, but writing papers, providing descriptive documentation, and giving public presentations was typically outside the scope of new employees' ability without several years of workplace training. However, one employee stated that significant preparation was gained from particular science and math courses that integrated communication skills. In addition, $\mathrm{PhD}$ advisors and graduate students were not aware of formal training in communication on their campus. Despite these perceived deficiencies in communication skills, it is apparently not a critical weakness for doing acceptable PhD-level research. Faculty advisors expect to assist in a long and deliberate apprenticeship in formal scientific writing and presentation. A manager of engineers did acknowledge that the PhDs in the company possessed some of the best writing and presentations skills, so informal writing training during the $\mathrm{PhD}$ process was recognized as providing significant additional communication skills.

\section{CONCLUSIONS}

Although the initial population is small, our findings suggest ways in which the undergraduate curriculum could adapt to better prepare students for academic and industrial careers. As our sample size increases by 10-fold over the coming years, we will obtain a better understanding of the diversity of skills, knowledge, and characteristics of employees who successfully transition into physics-related careers in academia and industry. In particular, our focus on workplace use of math, physics, and communication should keep our study in the mainstream of PER and Communication in the Disciplines research. Follow-up studies looking at other physics-related fields in other geographic regions are needed to understand the generalizability of these results. This work is supported by NSF DGE-1432578.
[1] National Science Foundation, Investing in science, engi-neering, and education for the nation's future NSF strate-gic plan for 2014-2018, March (2014).

[2] National Research Council, Rising Above the Gathering Storm: Energizing and Employing America for a Brighter Economic Future (National Academies Press, Washington, D.C., 2007).

[3] AIP Statistical Research Center, Latest employment data https://www.aip.org/statistics/employment/. APS/

[4] AAPT Joint Task Force on Undergraduate Physics Programs, http://www.compadre.org/jtupp/.
[5] National Research Council, Discipline-Based Education Re-search: Understanding and Improving Learning in Un-dergraduate Science and Engineering (National Academies Press, 2012).

[6] Linda Wang, "Closing the skills gap," Chemical \& Engi-neering News 90, 49-51 (2012).

[7] National Photonics Initiative, Lighting the Path to a Com-petitive, Secure Future (2013). 